\title{
Muscle weakness associated with H7N9 infection: report of two cases
}

\author{
Chao-Nan Jin ${ }^{1}$ and Ling-Ling Tang ${ }^{2^{*}}$ (D)
}

\begin{abstract}
Background: The emerging avian influenza A (H7N9) virus, a subtype of influenza viruses, was first discovered in March 2013 in China. Infected patients frequently present with pneumonia and acute respiratory disorder syndrome with high rates of intensive care unit admission and death. Neurological complications, such as Guillain-Barré syndrome(GBS), and intensive care unit-acquired weakness, including critical illness polyneuropathy and myopathy, have only rarely been reported previously.

Case presentation: In this study, we report on two Chinese patients with H7N9 severe pneumonia presenting neurological complications. These two patients had non-immune diseases prior to the onset of virus infection. A 56year-old female patient (case 1) and a 78-year-old female patient (case 2) were admitted because of fever, cough, chest tightness and shortness of breath. These patients were confirmed to have H7N9 infection soon after admission followed by the development of acute respiratory distress syndrome and various severe bacterial and fungal infections. The case 1 patient was found to have muscle weakness in all extremities after withdrawing the mechanical ventilator, and the case 2 patient was found when withdrawing extracorporeal membrane oxygenation, both of these conditions prolonged ventilator-weaning time. Furthermore, the case 1 patient carried the H7N9 virus for a prolonged period, reaching 28 days, and both of them stayed in the hospital for more than two months. A clinical diagnosis of intensive care unit-acquired weakness could be confirmed. However, based on results from electrophysiological testing and needle electromyography of these 2 patients, it is difficult to differentiate critical illness polyneuropathy from GBS, since no lumbar puncture or muscle and nerve biopsy were conducted during hospitalization. Following a long-term comprehensive treatment, the patients' neurological condition improved gradually.

Conclusions: Although there is great improvement in saving severe patients' lives from fatal respiratory and blood infections, it is necessary to pay sufficient attention and to use more methods to differentiate GBS from intensive care unit-acquired weakness. This unusual neurological complication could result in additional complications including ventilator associated pneumonia, prolonged hospital stay and then would further increase the death rate, and huge costs.
\end{abstract}

Keywords: H7N9, ICU-acquired weakness, Muscle weakness, Case report, Guillain-Barré syndrome

\section{Background}

The first human avian influenza H7N9 cases were reported in March of 2013 in China. Most of these cases had a history of recent exposure to poultry. Associated with severe and fatal respiratory disease, avian influenza A (H7N9) virus was so fatal that many persons with confirmed H7N9 virus infection were critically ill, almost

\footnotetext{
* Correspondence: 1196040@zju.edu.cn

${ }^{2}$ Department of Infectious Disease, The State Key Laboratory for Diagnosis and Treatment of Infectious Disease, Collaborative Innovation Center for Diagnosis and Treatment of Infectious Diseases, The First Affiliated Hospital, College of Medicine, Zhejiang University, Hangzhou 310003, China Full list of author information is available at the end of the article
}

$100 \%$ of cases were hospitalized, and $34 \%$ of them died. [1] Apart from the occurrence of acute respiratory distress syndrome (ARDS) and multi-organ failure, additional atypical clinical manifestations, such as neurological presentations, were associated with fatal avian influenza infection. Additional manifestations include seizures, encephalopathy and Guillan-Barré syndrome (GBS) [2], among which GBS is usually triggered by viral or bacterial infection and characterized by acute progressive symmetric limb weakness and areflexia. GBS has been reported to result from H1N1 infection [3-5]. Considering the severe conditions of H7N9 patients, 63\% [1] of whom were transferred to the intensive care unit, it is necessary to mention

(c) The Author(s). 2018 Open Access This article is distributed under the terms of the Creative Commons Attribution 4.0 International License (http://creativecommons.org/licenses/by/4.0/), which permits unrestricted use, distribution, and 
another neurological complication, intensive care unit-acquired weakness (ICUAW) [6-8], that frequently occurred in ICU patients. Additional neurological complications include critical illness polyneuropathy (CIP) and myopathy (CIM), the paralysis of which is typically symmetrical and affects predominantly proximal limb muscles and respiratory muscles, sparing facial and ocular muscles. In this study, we report the cases of patients infected with H7N9 who developed muscle weakness and were diagnosed with ICUAW, although we could not tell if it was CIP or GBS due to various factors.

\section{Case presentation \\ Case 1}

A 78-year-old female farmer diagnosed with H7N9 infection was referred to our hospital with a 7-day history of fever $\left(39.5^{\circ} \mathrm{C}\right)$, cough and chest tightness. She had a well-controlled 4-year history of hypertension and reported having had contact with a dead chicken. Examination revealed stable vital signs, normal muscle strength, a white blood cell count of $6.9 \times 10^{9} / \mathrm{l}$, a CRP of $229 \mathrm{mg} /$ $\mathrm{L}$, a creatine kinase of $83 \mathrm{U} / \mathrm{l}$, a creatine kinase-MB of $10 \mathrm{U} / \mathrm{l}$, a lactate dehydrogenase of $278 \mathrm{U} / \mathrm{l}$, an alanine aminotransferase of $23 \mathrm{U} / \mathrm{l}$, and an aspartate aminotransferase of $35 \mathrm{U} / \mathrm{l}$. A chest CT revealed the upper lobes on both sides, and the lower lobe of the left lung showed high-density and large-scale shadows. (Fig. 1a and b) She was treated with oral oseltamivir (150 mg twice), piperacillin tazobactam $4.5 \mathrm{~g}$ q8 $\mathrm{h}$, methylprednisolone ( $40 \mathrm{mg}$ once daily), intravenous immunoglobulin, as well as probiotics. Total parenteral nutrition was initiated and continued for 2 days with regular insulin (50 units, microinfusion pump) and was later changed to enteral nutritional suspension ( $500 \mathrm{ml}$ daily, nasal jejunal feeding tube). By $36 \mathrm{~h}$ after admission, her illness rapidly progressed with the development of ARDS. Oxygen therapy and mechanical ventilation were started along with a series of ventilator-associated pneumonia(VAP) prevention strategies, such as elevating the head from the bed by 30 degrees, careful oral care, and removal of subglottic secretions.

This patient fought a severe, mixed bacterial infection throughout the next two months in the hospital and even developed septic shock on day 15. During this period, intravenous peramivir, administered $300 \mathrm{mg}$ once daily, was added to the antiviral treatment on day 18 , and a chest CT scan revealed a better result on day 26 (Fig. 1c and d). Another 2 days later, the tests for H7N9 virus turned negative, use of midazolam and fentanyl were stopped, and withdrawal of mechanical ventilation was attempted. Until this time, a more complicated clinical condition of limbs and respiratory muscle weakness was present, with a physical examination revealing an upper limb proximal muscle strength measurement of level $0 / 5$, distal parts level 1/5, and lower limb muscle strength level

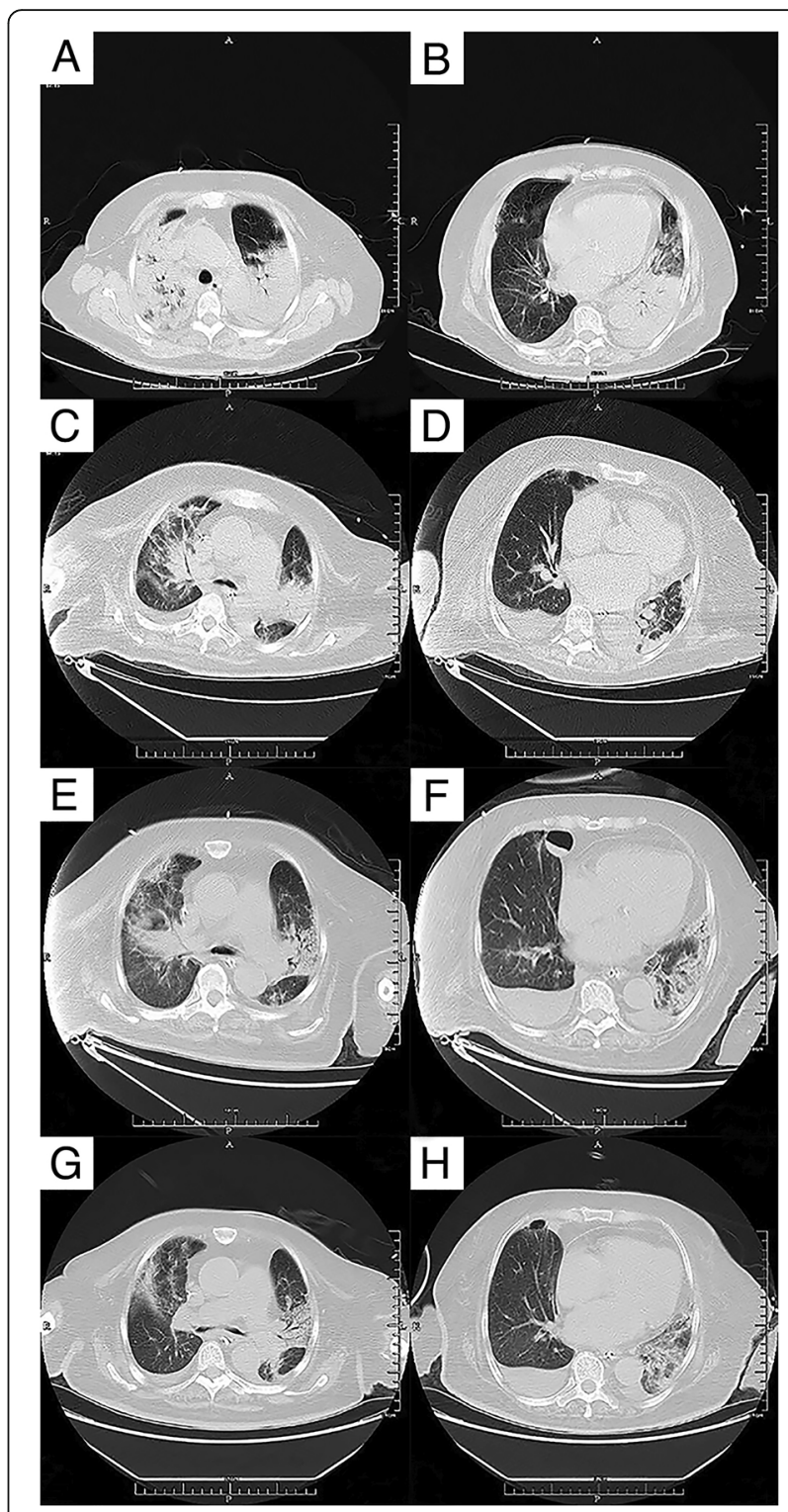

Fig. 1 Chest computed tomography findings in Case 1, which were examined at the time of therapeutic initiation ( $\mathbf{a}$ and $\mathbf{b}$ ), 2 days before the first time withdrawing the mechanical ventilation (c and $\mathbf{d}$ ), and in the clinical course of days 42 (e and $\mathbf{f}$ ) and 80 (g and $\mathbf{h}$ )

$0 / 5$. That of the right foot dropped significantly, and there were weak leg reflexes. Seat balance and standing balance could not be completed, which could not be explained by her improved pulmonary disease. Electrodiagnostic testing showed upper and lower limb peripheral nerve damage, which was managed with long-term neurotrophic drugs, combined with an immune-modulator, as well as physiotherapy. During this period, several attempts to withdraw the mechanical ventilation failed. A chest CT scan taken on day 42 showed that lesions had shrunk (Fig. 1e and f). Cough and other symptoms also alleviated gradually, and finally, she began absorbing oxygen via venturi mask one 
month later. The last chest CT scan was token on day 80 (Fig. $1 \mathrm{~g}$ and $\mathrm{h}$ ), and another 10 days later, she was discharged with a slight cough and expectoration and with no significant dry and wet rales heard. Her upper limb proximal muscle strength was measured at level $2 / 5$, distal parts at level $4 / 5$, and lower limb muscle strength at level $2 / 5$.

\section{Case 2}

A 56-year-old female patient was diagnosed with H7N9 infection and was transferred to the Emergency ICU of our hospital. She had a 3-day history fever $\left(40^{\circ} \mathrm{C}\right)$, cough with yellow sputum, chest tightness and shortness of breath. A chest CT scan from the local hospital showed bilateral lung infection and consolidation in part of the right lobe. She had had a resection of a meningioma brain tumour but had been well before admission. She reported having been to a live poultry market during the 2 weeks before disease onset. She had a fever $\left(38.8^{\circ} \mathrm{C}\right)$ and unstable vital signs when admitted. She showed a blood pressure of $79 / 53 \mathrm{mmHg}$ and an $\mathrm{SpO}_{2}$ of $83 \%$ under the application of a macadamized respiring ball charged with mechanical ventilator, morphine $30 \mathrm{mg}$ combined with midazolam and a combination administration of intravenous infusion via micro-pump dobutamine $100 \mathrm{mg}$, deslanoside $0.4 \mathrm{mg}$ and noradrenalin 10 $\mathrm{mg}$ to stable her blood pressure. Another examination revealed a white blood cell count of $1.5 \times 10^{9} / \mathrm{l}$, a CRP of $165.90 \mathrm{mg} / \mathrm{L}$, a creatine kinase of $199 \mathrm{U} / \mathrm{l}$, a creatine kinase-MB of $18 \mathrm{U} / \mathrm{l}$, a lactate dehydrogenase of $671 \mathrm{U} / \mathrm{l}$, an alanine aminotransferase of $19 \mathrm{U} / \mathrm{l}$, and an aspartate aminotransferase of $59 \mathrm{U} / \mathrm{l}$. A chest X-ray (Fig. 2a) showed bilateral large dense shadows and pleural effusion. Oseltamivir (150 mg, twice daily, nasal jejunal feeding tube) and peramivir (300 mg, once daily, intravenously), as well as methylprednisolone (40 mg, once daily, microinfusion pump), piperacillin tazobactam, intravenous immunoglobulin, pinaverium bromid, and probiotics were administered on day 1 . In addition, enteral nutritional suspension (500 ml daily, nasal jejunal feeding tube) was applied with regular insulin (50 units, microinfusion pump), as well as methycobal ( $500 \mu \mathrm{g}$ daily, microinfusion pump) to nitrite nerves.

However, her condition persistently deteriorated. On day 5 , she experienced refractory septic shock. After ineffective management of cardiopulmonary resuscitation and other rescue drugs, extracorporeal membrane oxygenation (ECMO) was initiated in combination with continuous renal replacement therapy because of anuria. Tests turned negative for H7N9 in the blood sample on day 10 , then we gradually stopped using anti-viral drugs and decided to remove ECMO. 10 days later, she was found to have muscle weakness when a physical examination revealed an upper limb muscle strength measured

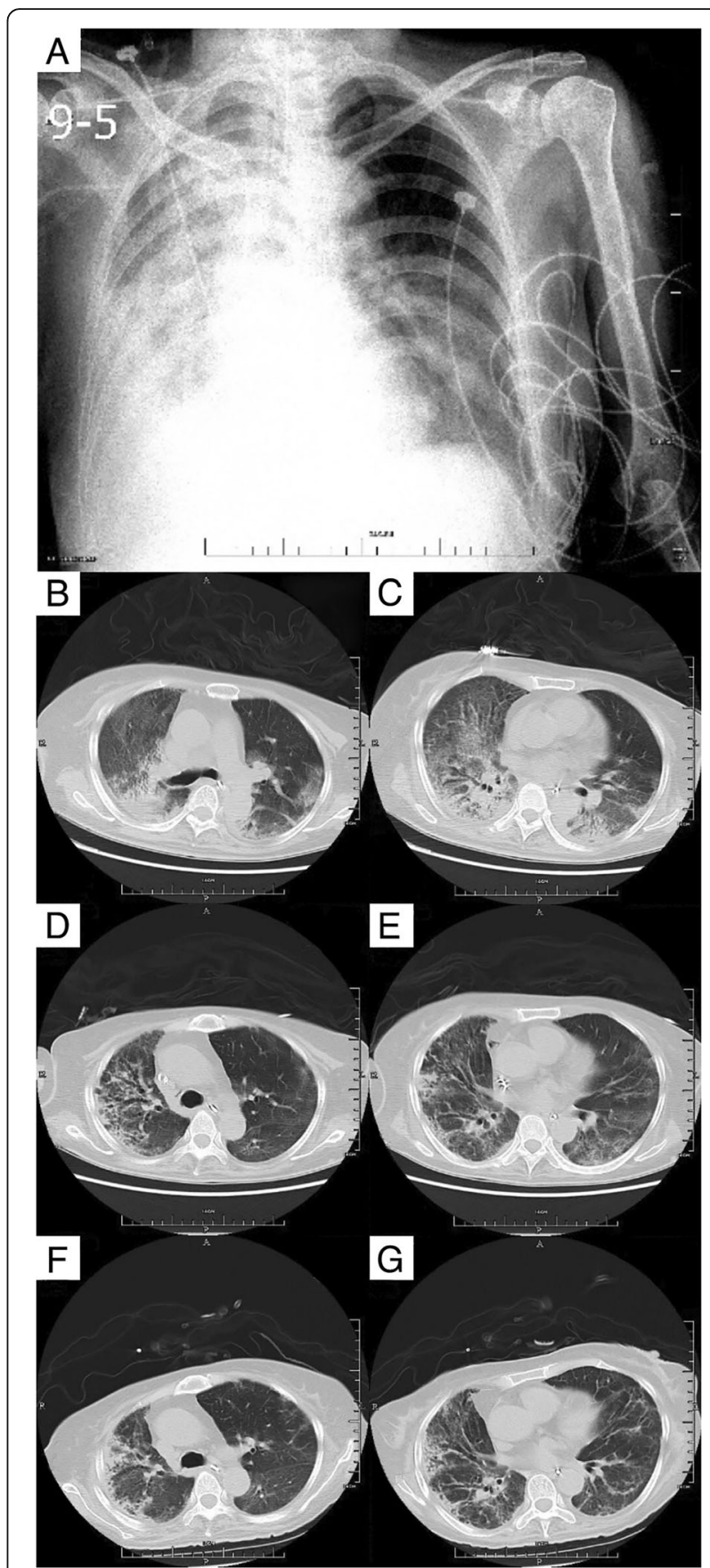

Fig. 2 Chest X-ray and chest computed tomography findings in Case 2, which were examined at the time of therapeutic initiation (a), 5 days after tests for H7N9 virus turned negative, on the day of mechanical ventilation withdrawal (b and $\mathbf{c}$ ), in the clinical course of day 31 (d and $\mathbf{e}$ ) and on the day of being discharged ( $\mathbf{f}$ and $\mathbf{g}$ )

at level $3 / 5$ with a lower level of $2 / 5$, which was bilateral. That of the distal parts was better than that of the proximal. When her vital signs became sufficiently stable, she received the first chest CT scan, which still revealed large dense shadows (Fig. $2 \mathrm{~b}$ and c). Electrodiagnostic testing showed upper and lower limb peripheral nerve 
damage. Nasal feeding of vitamins B1 and B2 along with long-term physiotherapy, on the basis of methycobal and an immune-modulator, were initiated, as well as strategies to prevent VAP. The next two months were a long battle against severe bacterial and fungi co-infections. A chest CT scan revealed slight absorption of the lesions at the left lung on day 31(Fig. 2d and e). At last, she was discharged on day 77 after taking a chest CT scan (Fig. 2f and g) with an upper limb muscle strength measurement of level $4 / 5$, lower limb distal of level $3 / 5$ minus, and proximal parts of level $2 / 5$.

\section{Discussion}

Antiviral treatment was associated with a reduction of viral load and death rate. In this report, case 1 presented a sustained viral shedding time of 28 days, while the median has been reported to be approximately 19 days after anti-viral treatment $[9,10]$. The main reason may be the late prescription of oseltamivir on day 8 in combination with peramivir on day 26 after the onset of illness, even though it has been reported that no obvious advantage is observed from antiviral treatment to viral-negative in oseltamivir-peramivir combination therapy comparing to oseltamivir monotherapy [11]. Another factor maybe associated is the application of corticosteroids, which could affect the viral shedding time on H7N9 patients [12] and may cause antiviral resistance in $\mathrm{A} / \mathrm{H} 7 \mathrm{~N} 9$ viruses [13]. In these two cases, we prescribed methylprednisolone as 40 mg daily for 13 days and cut off to half. More solid evidence, such as randomized controlled trials, on the effect of adjuvant corticosteroids administration on viral shedding time need to be conducted on H7N9 patients.

Among 167 H7N9 infected patients admitted in our hospital centre, 89 had a severe infection and were admitted in ICU with a mean duration of mechanical ventilation of 26.3 days. Two patients, reported herein, presented a muscle weakness when we tried to withdraw mechanical ventilation, at day 28 in case 1 and at day 20 in case 2 . These two patients presented bilateral and relatively symmetric flaccid weakness of the limbs with the involvement of respiratory without paralyzed cranial nerve-innervated muscles and developed decreased deep tendon reflexes, absence of an alternative diagnosis for weakness, which are consistent with Brighton Working Group clinical case definitions for GBS in level 3 certainty [14]. The diagnosis of ICUAW could be established according to the diagnosing standards [7], since features of these two critically ill patients almost matched all of risky factors of ICUAW reported before, including female, immobility, sepsis, persistent systemic inflammation, multi-organ system failure, hyperglycaemia, glucocorticoids, neuromuscular blocking agent, and bed rest $[6,15]$.

Furthermore, the values of CK remained in the normal range, except that upon admission, the electrophysiological examination result showed that both sensory and motor nerves were injured. This finding is more similar to CIP than CIM in ICUAW. However, electrophysiological examination enabled a diagnosis of GBS at level 1 certainty or CIP, since they both include axonal motor and sensory injury, polyneuropathy in electrophysiological feathers as part of definition. Furthermore, the condition of being on a sedative for a long time made it more difficult for observing a complete course. In addition, there are about 4 to 7 cases of influenza related GBS per 100,000 cases of influenza [16] and it has been reported that H1N1 influenza is more likely to be associated with heightened neurological complications comparing to seasonal influenza [17]. Therefore, we cannot exclude the possibility of the H7N9 virus itself contributing and resulting in paralysis roughly.

In conclusion, it is surprising, though educational, that these two mechanically ventilated patients were hospitalized for more than two months, 90 and 77 days for each, since they both experienced ARDS, severe bacterium and fungal infection, and respiratory muscle weakness. These complications resulted in ventilatory failure and, in turn, increased the possibility of VAP, which is the most common nosocomial infection in mechanically ventilated patients. There are many aspects that we can improve. Throughout the whole disease course, a series of prevention methods, such as intensive insulin therapy and passive roll over, are needed daily, as well as prevention of VAP [18].

Even though early investigation of muscle weakness is challenging, since mechanically ventilated patients are always sedated, physical examinations, especially neurological, for critically ill patients [19] are needed several times per day and should be recorded in detail. As patients gradually become alert, muscle strength should be tested in functional limb muscle groups using the Medical Research Council scale [20] or handheld dynamometry [21] to estimate the severity of force-generating impairments. This estimation is particularly important in patients with immune-mediated polyneuropathies [22], including GBS. To further differentiate between GBS and CIP, several procedures are important such as lumbar puncture, blood testing including tests for anti-GM1 antibodies, and anti-GQ1b and anti-GD1a IgG antibodies, and muscle and nerve biopsies.

\section{Abbreviations \\ ARDS: Acute respiratory distress syndrome; CIM: Critical illness myopathy; CIP: Critical illness polyneuropathy; ECMO: Extracorporeal membrane oxygenation; GBS: Guillain-Barré syndrome; ICUAW: Intensive care unit- acquired weakness; VAP: Ventilator-associated pneumonia}

\section{Acknowledgements}

The abstract has been presented as a poster on 7th International Conference on Bacteriology and Infectious Diseases in Osaka, Japan, on June 4-5, 2018, accepted by J Bacteriol Parasitol 2018, Volume 9, https://doi.org/10.4172/ 2155-9597-C1-047 


\section{Funding}

This research was supported by a grant from the National Science and Technology Major Project (2017ZX10204401), which retrospectively supported this clinical study.

\section{Availability of data and materials}

The datasets used during the current study are available from the corresponding author on reasonable request.

\section{Authors' contributions}

Both the authors have contributed significantly and all authors are in agreement with the content of the manuscript. CNJ-the first author carried out the data collection, literature review and drafting of the manuscript. LLTthe corresponding author made substantial contributions to conceptions and revised it critically for important intellectual content. Both authors have read and approved the final manuscript.

\section{Ethics approval and consent to participate}

Ethical approval for this investigation was obtained from the Research Ethics Committee of the First Affiliated Hospital, College of Medicine, Zhejiang University.

\section{Consent for publication}

Written informed consent was obtained from the patients for publication of this case report and any accompanying images. A copy of the written consent is available for review by the Editor-in-Chief of this journal.

\section{Competing interests}

The authors declare that they have no competing interests.

\section{Publisher's Note}

Springer Nature remains neutral with regard to jurisdictional claims in published maps and institutional affiliations.

\section{Author details}

${ }^{1}$ State Key Laboratory for Diagnosis and Treatment of Infectious Diseases, The First Affiliated Hospital, School of Medicine, Zhejiang University, Hangzhou, China. ${ }^{2}$ Department of Infectious Disease, The State Key Laboratory for Diagnosis and Treatment of Infectious Disease, Collaborative Innovation Center for Diagnosis and Treatment of Infectious Diseases, The First Affiliated Hospital, College of Medicine, Zhejiang University, Hangzhou 310003, China.

Received: 6 May 2018 Accepted: 6 December 2018

Published online: 20 December 2018

\section{References}

1. Li Q, Zhou L, Zhou M, Chen Z, Li F, Wu H, Xiang N, Chen E, Tang F, Wang D, et al. Epidemiology of human infections with avian influenza a(H7N9) virus in China. N Engl J Med. 2014;370(6):520-32.

2. Ekstrand JJ. Neurologic complications of influenza. Semin Pediatr Neurol. 2012;19(3):96-100.

3. Cardenas G, Soto-Hernandez JL, Diaz-Alba A, Ugalde Y, Merida-Puga J, Rosetti M, Sciutto E. Neurological events related to influenza a (H1N1) pdm09. Influenza Other Respir Viruses. 2014;8(3):339-46.

4. Chaari A, Bahloul M, Dammak H, Nourhene G, Rekik N, Hedi C, Chokri BH, Bouaziz M. Guillain-Barre syndrome related to pandemic influenza a (H1N1) infection. Intensive Care Med. 2010;36(7):1275.

5. Kutlesa M, Santini M, Krajinovic V, Raffanelli D, Barsic B. Acute motor axona neuropathy associated with pandemic H1N1 influenza a infection. Neurocrit Care. 2010;13(1):98-100.

6. Jolley SE, Bunnell AE, Hough CL. ICU-acquired weakness. Chest. 2016;150(5): 1129-40.

7. Latronico N, Bolton CF. Critical illness polyneuropathy and myopathy: a major cause of muscle weakness and paralysis. Lancet Neurol. 2011;10(10): 931-41.

8. Zorowitz RD. ICU-acquired weakness: a rehabilitation perspective of diagnosis, treatment, and Functional Management. Chest. 2016;150(4):966-71.

9. Shen Y, Lu H, Qi T, Gu Y, Xiang M, Lu S, Qu H, Zhang W, He J, Cao H, et al. Fatal cases of human infection with avian influenza a (H7N9) virus in Shanghai, China in 2013. Biosci Trends. 2015;9(1):73-8.
10. Gao HN, Lu HZ, Cao B, Du B, Shang H, Gan JH, Lu SH, Yang YD, Fang Q, Shen YZ, et al. Clinical findings in 111 cases of influenza a (H7N9) virus infection. N Engl J Med. 2013;368(24):2277-85.

11. Zhang Y, Gao H, Liang W, Tang L, Yang Y, Wu X, Yu L, Chen P, Zheng S, Ou $\mathrm{H}$, et al. Efficacy of oseltamivir-peramivir combination therapy compared to oseltamivir monotherapy for influenza a (H7N9) infection: a retrospective study. BMC Infect Dis. 2016;16:76.

12. Cao B, Gao H, Zhou B, Deng X, Hu C, Deng C, Lu H, Li Y, Gan J, Liu J, et al. Adjuvant corticosteroid treatment in adults with influenza a (H7N9) viral pneumonia. Crit Care Med. 2016;44(6):e318-28.

13. Hu Y, Lu S, Song Z, Wang W, Hao P, Li J, Zhang X, Yen HL, Shi B, Li T, et al, Association between adverse clinical outcome in human disease caused by novel influenza a H7N9 virus and sustained viral shedding and emergence of antiviral resistance. Lancet (London, England). 2013;381(9885):2273-9.

14. Sejvar JJ, Kohl KS, Gidudu J, Amato A, Bakshi N, Baxter R, Burwen DR, Cornblath DR, Cleerbout J, Edwards KM, et al. Guillain-Barre syndrome and fisher syndrome: case definitions and guidelines for collection, analysis, and presentation of immunization safety data. Vaccine. 2011;29(3):599-612.

15. Patel BK, Pohlman AS, Hall JB, Kress JP. Impact of early mobilization on glycemic control and ICU-acquired weakness in critically ill patients who are mechanically ventilated. Chest. 2014;146(3):583-9.

16. Sivadon-Tardy V, Orlikowski D, Porcher R, Sharshar T, Durand MC, Enouf V, Rozenberg F, Caudie C, Annane D, van der Werf S, et al. Guillain-Barre syndrome and influenza virus infection. Clin Infect Dis. 2009;48(1):48-56.

17. Ekstrand JJ, Herbener A, Rawlings J, Turney B, Ampofo K, Korgenski EK, Bonkowsky JL. Heightened neurologic complications in children with pandemic H1N1 influenza. Ann Neurol. 2010;68(5):762-6.

18. Keyt H, Faverio P, Restrepo Ml. Prevention of ventilator-associated pneumonia in the intensive care unit: a review of the clinically relevant recent advancements. Indian J Med Res. 2014;139(6):814-21.

19. Sharshar T, Citerio G, Andrews PJ, Chieregato A, Latronico N, Menon DK, Puybasset L, Sandroni C, Stevens RD. Neurological examination of critically ill patients: a pragmatic approach. Report of an ESICM expert panel. Intensive Care Med. 2014;40(4):484-95.

20. Kleyweg RP, van der Meche FG, Schmitz PI. Interobserver agreement in the assessment of muscle strength and functional abilities in Guillain-Barre syndrome. Muscle Nerve. 1991:14(11):1103-9.

21. Andrews AW, Thomas MW, Bohannon RW. Normative values for isometric muscle force measurements obtained with hand-held dynamometers. Phys Ther. 1996;76(3):248-59.

22. Merkies IS, Schmitz PI, Samijn JP, Meche FG, Toyka KV, van Doorn PA. Assessing grip strength in healthy individuals and patients with immunemediated polyneuropathies. Muscle Nerve. 2000;23(9):1393-401.

Ready to submit your research? Choose BMC and benefit from:

- fast, convenient online submission

- thorough peer review by experienced researchers in your field

- rapid publication on acceptance

- support for research data, including large and complex data types

- gold Open Access which fosters wider collaboration and increased citations

- maximum visibility for your research: over $100 \mathrm{M}$ website views per year

At $\mathrm{BMC}$, research is always in progress.

Learn more biomedcentral.com/submissions 